\title{
Does Ringer Lactate Used in Parkland Formula for Burn Resuscitation Adequately Restore Body Electrolytes and Proteins?
}

\author{
Medhat E. Habib', Loai M. Saadah², Mazen Al-Samerrae3, Fathy E. Shoeib4, \\ Mahaba Mamoun', Gehan A. Latif ${ }^{5}$, Dalia M. Habib ${ }^{6}$ \\ ${ }^{1}$ Department of Plastic \& Reconstructive Surgery, Zayed Military Hospital, Abu Dhabi, UAE \\ ${ }^{2}$ Department of Pharmacy, Zayed Military Hospital, Abu Dhabi, UAE \\ ${ }^{3}$ Department of Plastic and Reconstructive Surgery, Burn Unit, Mafraq Hospital, Abu Dhabi, UAE \\ ${ }^{4}$ Department of Plastic and Reconstructive Surgery, Burn Unit, Khoula Hospital, Mucat, Sultanate of Oman \\ ${ }^{5}$ Advancing Clinical Pathology Group, Abu Dhabi, UAE \\ ${ }^{6}$ Faculty of Medicine, Cairo University, Cairo, Egypt \\ Email: medhatemil1@hotmail.com
}

How to cite this paper: Habib, M.E., Saadah, L.M., Al-Samerrae, M., Shoeib, F.E., Mamoun, M., Latif, G.A. and Habib, D.M. (2017) Does Ringer Lactate Used in Parkland Formula for Burn Resuscitation Adequately Restore Body Electrolytes and Proteins? Modern Plastic Surgery, 7, 1-12. https://doi.org/10.4236/mps.2017.71001

Received: December 31, 2016

Accepted: January 24, 2017

Published: January 27, 2017

Copyright $\odot 2017$ by authors and Scientific Research Publishing Inc. This work is licensed under the Creative Commons Attribution International License (CC BY 4.0).

http://creativecommons.org/licenses/by/4.0/

\begin{abstract}
Objective: Evaluation of the effect of Ringer Lactate, as the resuscitative burn fluid according to Parkland Formula, on restoring the levels of body electrolytes and proteins. Design: A retrospective cohort study. Setting: The National Burns Unit, Mafraq Hospital, Abu Dhabi, United Arab Emirates (UAE). Patients: One hundred and fifteen patients admitted with fresh burns between 1st of January 2011 and 31st of December 2013, who met inclusion and exclusion criteria. Methods: Team collected demographic and clinical data for each patient using a standard form. Patients received Ringer Lactate solely as the resuscitative burn fluid according to Parkland Formula. Baseline (pre-) and third-day (post-) variables included levels of sodium, potassium, chloride, proteins, and albumin. Researchers then performed paired comparisons of serum electrolytes and protein levels. Results: Mean values showed maintenance of the potassium and chloride levels within the normal range after administering the Ringer Lactate, significant decline in sodium, and a marked hypoproteinaemia and hypoalbuminaemia post-resuscitation. Conclusions: Ringer Lactate used as the mere resuscitative post burn fluid is suboptimal. Sodium supplementation may be required to correct hyponatremia. Colloids, preferably intravenous albumin should be added, as advised by the original Parkland Formu-
\end{abstract} la.

\section{Keywords}

Ringer Lactate, Burn, Parkland, Electrolytes, Proteins 


\section{Introduction}

Fluids constitute the most important health-related intervention in patients with moderate to severe burns [1] [2]. Therefore, centers managing these cases use different models for resuscitation [3] [4] [5]. Of these, the majority of centers apply the Parkland formula in selecting and calculating requirements from available and recommended intravenous fluid formulations [6] (Equation (1))

Total amount of fluids needed ${ }^{+}=4 \mathrm{ml} \times \% \mathrm{BSA} \times$ Weight $(\mathrm{Kg})$.

\%TBSA is the total body surface area burned calculated using the well-known Lund and Browder assessment chart.

${ }^{+}$One of half of this amount is given in the first 8 hours after the burn event and the remaining half is given over the next 16 hours. Also the original Parkland Formula used colloids on the second day of the burns but this is neglected in most of the burns centers.

In this formula, clinicians approximate the percent of total body surface area (\%TBSA) burned using one or a combination of a number of methods; namely, Lund-Browder [7] [8] [9], Rule of Nines [10] [11], and Palm [12] [13] [14]. In addition, they may account for gender differences in \%TBSA while arriving at these estimates [15]. Regardless of these considerations, crystalloids comprise the preferred fluids in this resuscitation model with Ringer Lactate (RL) being the agent of first choice for most practitioners. Although research groups have used new components such as ethyl pyruvate together with RL, survival benefits with such mixtures in animal models of burns await clinical confirmation [16].

Use of Colloids such as intravenous (I.V.) albumin or hypertonic saline is controversial. Albumin for example is more expensive and a meta analysis of 24 trials involving 9920 patients demonstrates that it fails to improve survival when compared with crystalloids [17]. Similarly, hypertonic crystalloid saline has been associated with renal failure and death in one observational study and seems to offer no added benefit to isotonic solutions [18] [19]. However, there is a resurgence in interest in albumin and a relatively recent study [20] having shown that albumin levels of less than about $2 \mathrm{~g} / \mathrm{dl}(20 \mathrm{~g} / \mathrm{L})$ emerged with the highest sensitivity and specificity for mortality. It preceeded variables such as flame, fullthickness, or inhalation injuries, burns affecting $>30 \%$ of the body surface area and those associated with infection. Moreover, reviewers of colloids use in burn patients document multiple positive actions for albumin and more questions that need clarifications and answers. For example, although albumin provides better maintenance of intravascular volume and cardiac output as well as less edema, the effect of its continuous supplementation in or following the acute resuscitation phase remains less well understood [21]. In fact, studies which conclude lack of usefulness of albumin or other colloids' use outcomes that are broad such as mortality and ignore the immediate effects that the different fluids have on serum electrolyte as well as protein levels. Furthermore, there is paucity of published information on burn injuries and their management in the United Arab 
Emirates (UAE) as well as nearby countries in the Middle East and North Africa (MENA) and Gulf Corporation Council (GCC) regions. Hence we conducted this study to resolve some of the uncertainties that exist in the area of fluid resuscitation while enriching literature with data from our region. Specifically, we aimed at answering a simple question; what effects do crystalloids or RL used as the sole fluid for resuscitation have on the serum levels of sodium, potassium, chloride, albumin, and total proteins?

\section{Patients and Methods}

\subsection{Definitions}

Shock period is defined as the thirty six hours post burn. Hyponatremia was defined as a blood level of less than $135 \mathrm{mEq} / \mathrm{L}$ whereas hypernatremia is any reading more than $145 \mathrm{mEq} / \mathrm{L}$. Hypokalemia is present when potassium levels are below $3.4 \mathrm{mEq} / \mathrm{L}$ in children or $3.5 \mathrm{mEq} / \mathrm{L}$ in adolescent and adults. Hyperkalemia is potassium reading more than $4.7 \mathrm{mEq} / \mathrm{L}$ in children and $5.2 \mathrm{mEq} / \mathrm{L}$ in adolescents and adults. Hypocholermia and hypercholermia are met when the chloride concentration is below $96 \mathrm{mEq} / \mathrm{L}$ and above $106 \mathrm{mEq} / \mathrm{L}$, respectively. Hypoalbuminemia and hyperalbuminemia mean levels of less than 34 and more than $54 \mathrm{~g} / \mathrm{L}$, respectively. Whereas hypoproteinemia and hyperproteinemia are present when levels decrease below $64 \mathrm{~g} / \mathrm{L}$ and rise above $83 \mathrm{~g} / \mathrm{L}$, respectively.

\subsection{Inclusion and Exclusion Criteria}

The patients included in the study are those who fulfilled the following criteria:

A. Children with burns of $>10 \%$ and adults of $>15 \%$ of their total body surface area assessed according to the Lund and Browder chart.

B. Patients who received RL solution as the resuscitative intravenous fluid during the burn shock period according to Parkland Formula.

C. Patients who had their blood investigations done within 6 hours from the start time of the burn and not the time of admission. This initial blood investigation reading is used as a baseline (pre-) against which the change in the electrolytes and proteins is compared at the end of the shock period by another blood collection within 3 days from the time of burn. This second blood investigation (post-) is collected after the patient received the RL for at least 1 day and before the end of the 3rd post burn day.

All patients who did not fulfill the above mentioned criteria were excluded from the study.

\subsection{Setting}

Study site comprises the main facility which provides healthcare services to the UAE burn patients in the Emirate of Abu Dhabi. Mafraq hospital has an approximately 451 total bed size. The burn unit consists of 10 beds with about $80 \%$ occupancy. Average annual census of the unit is 170 cases. All the beds are provided with full ventilator facilities. 


\subsection{Team}

The team usually consists of a consultant plastic surgeon with 2 specialists and one resident. Other disciplinary members also involve ICU physicians, infectious diseases doctors, clinical pharmacists, physiotherapists and dieticians. Plastic surgery team and clinical pharmacists collected and validated data.

\subsection{Procedure}

Team developed a standardized data collection tool and definitions. Plastic Surgeons and clinical pharmacists retrospectively filled these forms anonymously. Another staff validated first 5 cases of each investigator. Data included patient and staff codes, demographics, age, and gender, estimated \%TBSA, cause of burn, baseline, and post resuscitation levels of sodium, potassium, chloride, albu$\mathrm{min}$, and total protein. Laboratory performed data measurements with standardized procedures and kits and reported them with common units and reference ranges. Local hospital ethics committee approved the study and our team conducted this study in full compliance with the ethical standards presented in the declaration of Helsinki.

\subsection{Statistical Analyses}

Authors present continuous data with average \pm standard deviation and categorical data with ratios or percentages. They performed no simulation or replacement of missing data in both cases. Data keeper performed a paired comparison of the baseline and post resuscitation levels of sodium, potassium, chloride, albumin, and total protein when both values were available. He used a paired t-test whenever data followed a normal distribution. If the data deviated from the normality assumption, data keeper used non-parameteric tests. Team used Stat Tools, Version 6.3.0 (Palisades Corp, Ithaca, NY). In all univariate analyses, the team a priori considered a p-value of less than 0.05 as statistically significant. However, data analyst determined that multivariate analyses were not possible.

\section{Results}

461 patients with fresh burns were admitted to the Unit during the period from January 2011 till December 2013. Only 115 patients fulfilled the inclusion/exclusion criteria and were recruited in this study (Figure 1). Forty five patients were excluded because their \%TBSA was less than $10 \%$ or $15 \%$ for children and adults, respectively. One hundred and sixty two patients were referrals from other hospitals and did not receive RL during shock period. Another one hundred and thirty nine patients had their laboratory investigations done outside the time windows defined a priori. We present the baseline and demographic characteristics of the patients and burn injuries in Table 1. Eighty percent of the patients were more than 12 years old and most were males (almost 6:1 ratio). Less than $50 \%$ of the patients had burns affecting more than $30 \%$ of their body surface area. Majority of burns were due to flame (71\%) and scalds (19\%) or heat (i.e. scald, steam, and liquids) (23\%). These and other types of burns encountered in this cohort are 
461Burn patients from January 2011 till December 2013

45 TBSA $\%$ not meeting $1^{\text {st }}$ inclusion criteria ( 38 children $<10 \%$ and 7 adults $<15 \%$ burns).

162 referred from other hospitals did not receive RL solution during shock period.

47 had their initial blood investigations done after 6 hours of sustaining the burns.

92 had their blood investigations repeated after 3 days

115Burn patients met all inclusion criteria

Figure 1. Total number of patients admitted to the burn unit and numbers of excluded cases with their reasons.

Table 1. Cohort baseline characterisitics.

\begin{tabular}{cc}
\hline Variable & Categories (N) or Mean \pm Standard Deviation \\
\hline Age & $27.3 \pm 16.0$ years \\
Age Categories & $\leq 12$ years old (23) \\
& $>12$ years old (92) \\
Gender & M: Male (98) \\
\%TBSA & F: Female (17) \\
& $<30 \%(65)$ \\
& 30 to $<60 \%(33)$ \\
Cause & $\geq 60 \%(17)$ \\
& Alkali (1) \\
& Chemical (2) \\
& Coffee (1) \\
Electrical (3) & Flame (82) \\
Friction (1) \\
Food (1) \\
Scald (22) \\
Steam (3) \\
Lightning (1)
\end{tabular}

Abbreviations: N; number of patients, \%TBSA; percent of total body surface affected.

summarized in Figure 2. Survival during the shock period was $100 \%$ and vital signs were maintained while fluids were adjusted accordingly.

Electrolytes assessed in the study were sodium, potassium and chloride. Twenty one patients (18.3\%) had hyponatraemia at the time of admission. The number increased to 55 patients (47.8\%) at the end of the resuscitation period. One patient 


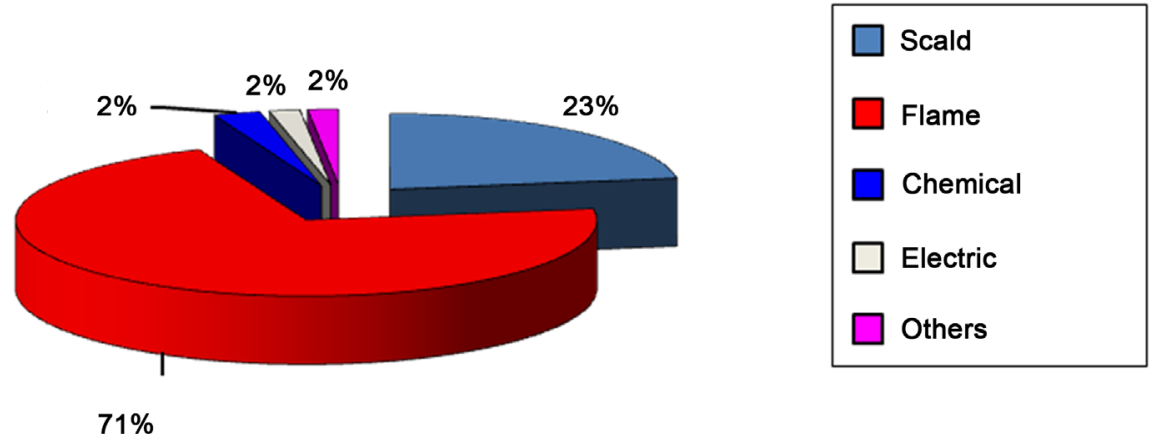

Figure 2. Types (causes) of burns encountered in cohort in this study in percentages.

was admitted with hypernatraemia $(0.9 \%)$ and 6 patients had hypernatraemia at the end of the shock period (5.2\%). Pre- and post-sodium levels are presented in Figure 3. Overall, there was a statistically significant decrease in sodium levels post-resuscitation. Subgroups with larger samples; namely, male patients, those with \%TBSA of less than $30 \%$, as well as adolescent and adult patients had greater and significant dips in sodium.

Thirty patients had hypokalaemia at the time of admission (26.1\%). The number reduced to 16 patients by the end of resuscitation period (13.9\%). Four patients were admitted with initial hyperkalaemia (3.4\%) and two had post infusion hyperkalaemia (1.7\%). Pre- and post-potassium levels are presented in Figure 4. Overall, there was a trend towards raising the potassium level post-resuscitation although it did not reach statistical significance ( $\mathrm{p}$ value $<0.05$ ). Larger subgroups; namely, males, those with $\% \mathrm{TBSA}<30 \%$, and adolescents and adults, were once again more likely to witness significant increases in potassium levels.

No patients had hypochloraemia in this study. However, 39 patients had hyperchloremia (33.9\%) initially and 34 (29.6\%) had hyperchloremia post-resusciation. Overall, there was no change in chloride levels in blood and only patients with \%TBSA less than $30 \%$ (pre- $104.1 \pm 3.4 \mathrm{mEq} / \mathrm{L}$ vs. post- $103.0 \pm 3.9$, p value 0.03 ) or more than or equal to $60 \%$ (pre- $106.9 \pm 5.1$ vs. post- $110.9 \pm 5.5$, p value 0.02 ) had significant reduction or increase in chloride levels, respectively.

Out of 82 patients assessed (available data) for albumin level, 23 patients had hypoalbuminaemia at the time of admission (28.0\%). The number markedly increased to 79 patients by the end of the resuscitation period (96.3\%). None of the patients had hyperalbuminaemia in our study. In addition, 6 and 15 patients had albumin levels of less than $20 \mathrm{~g} / \mathrm{L}$ initially and after the resuscitation period, respectively. We assessed total protein in blood in 81 patients with available data. While the initial reading of patients showed that 33 of them had hypoproteinaemia (40.7\%), 78 patients had hypoproteinaemia by the end of the resuscitation period (96.3\%). No patients had hyperprotinaemia in our study. Figure 5 and Figure 6 summarize the levels found on admission and post-resuscitation for albumin and total protein, respectively. Overall and in all subgroup comparisons albumin and total protein levels were significantly reduced at the end of burn shock phase (All $\mathrm{p}$ values $<0.05)$. 


\section{Sodium Pre-Level}

128

135

138139

147

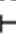

Sodium Post-Leve

127

133

135

138

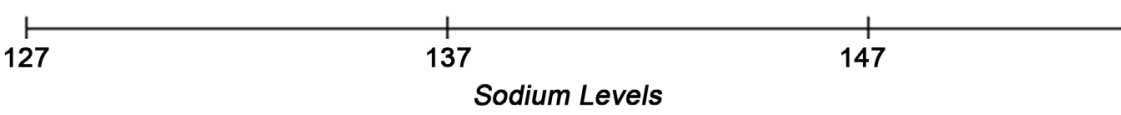

Figure 3. Pre- and post-sodium levels using two-tailed paired t-test.

Potassium Pre-Level

\begin{tabular}{lllll}
2.6 & 3.4 & 3.7 & 4.15 & 5.6 \\
\hline
\end{tabular}

\section{Potassium Post-Level}

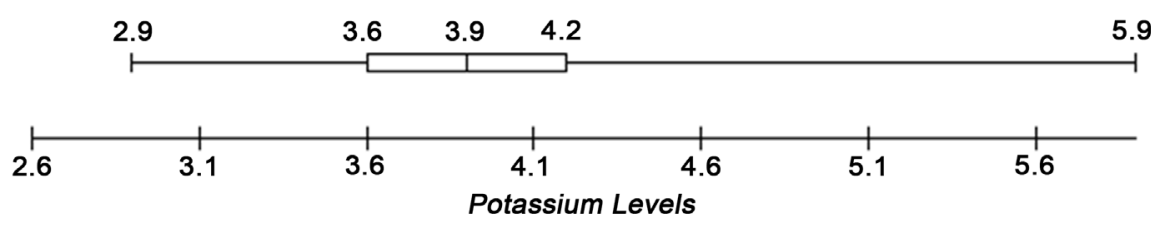

Figure 4. Pre- and post-potassium levels using two-tailed paired t-test.

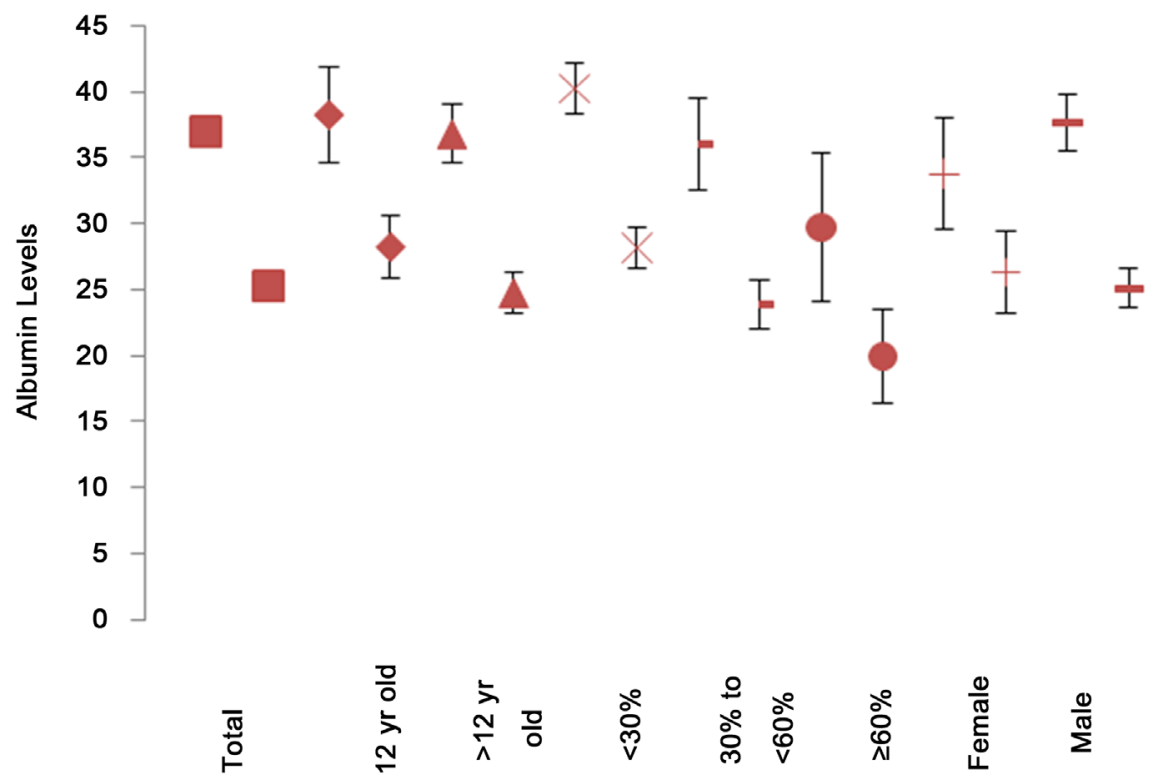

Figure 5. Pre- and post-albumin levels for total number of cases and in various subgroups with error bounds of $95 \%$ confidence intervals. In total and subgroup analyses, pre-albumin levels were all significantly reduced as evident in the post-albumin levels (All $\mathrm{p}$ values $<0.05)$.

\section{Discussion}

This study is the first in GCC and MENA regions, to the best of our knowledge, that demonstrates that management of burn patients in the shock phase with 


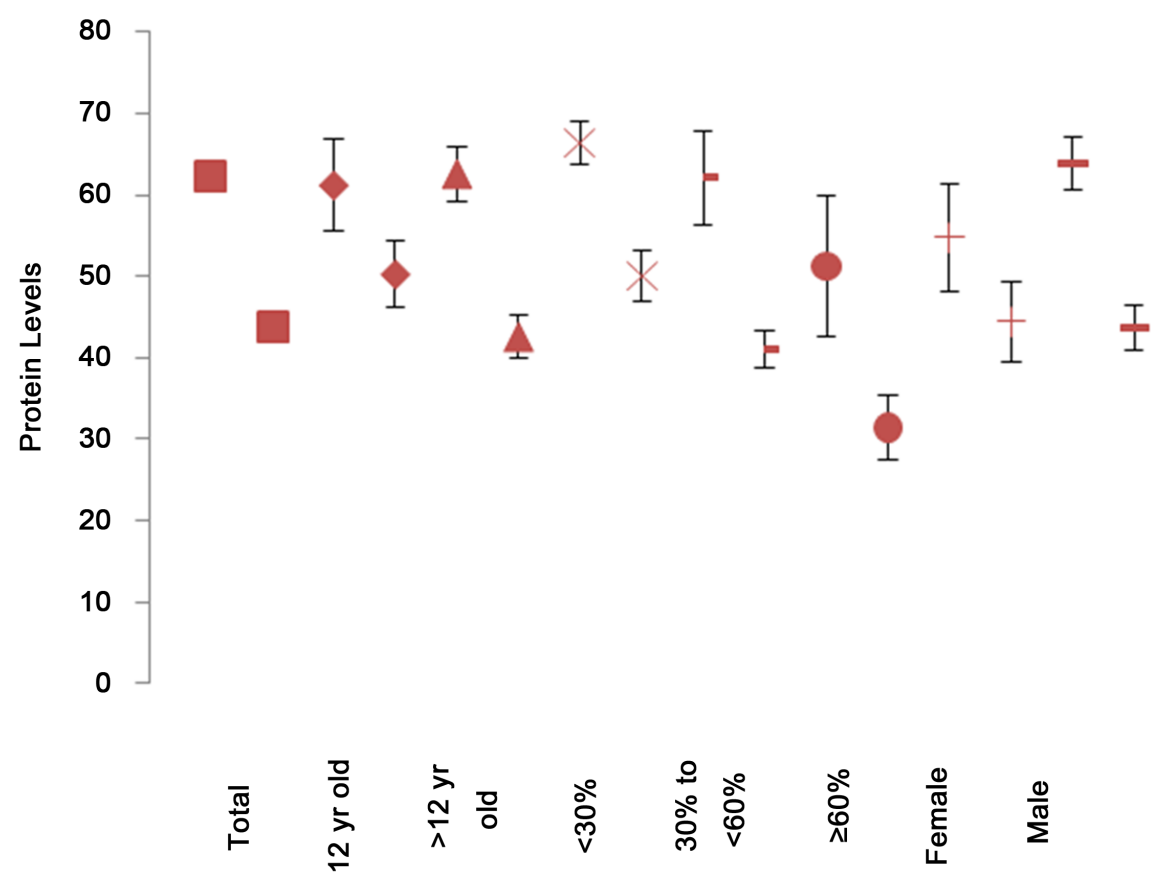

Figure 6. Pre- and post-protein levels for total number of cases and in various subgroups with error bounds of $95 \%$ confidence intervals. In total and subgroup analyses, pre-albumin levels were all significantly reduced as evident in the post-albumin levels (All p values $<0.05)$.

lactated ringer may be insufficient. There is a limited number of up to date literature directly investigating the effect of resuscitation of burn patients with lactated ringers (LR) in terms of electrolytes balance. LR contains physiologic concentrations of major electrolytes and lactate (one liter of Ringer's lactate solution contains: $130 \mathrm{mEq}$ of sodium, $109 \mathrm{mEq}$ of chloride, $28 \mathrm{mEq}$ of lactate, $4 \mathrm{mEq}$ of potassium, and $3 \mathrm{mEq}$ of calcium ion) [22]. These amounts reflect those found in blood, except for sodium, and would prevent hyperchloremic acidodsis (in our study chloride levels were maintained) as well as ensure patients remain in the normal potassium level range. Another solution that has similar constituents is Hartmann's Solution which contains for each one litre: $131 \mathrm{mEq}$ of sodium, $111 \mathrm{mEq}$ of chloride, $29 \mathrm{mEq}$ of lactate, $5 \mathrm{mEq}$ of potassium, $4 \mathrm{mEq}$ of calcium [23]. These solutions, however, fail to control sodium levels in such patients and are usually associated with hyponatremia. Specifically, RL seems to be insufficient in restoring the blood sodium back to $135-145 \mathrm{mmol} / \mathrm{L}$. On the other hand, studies in animal models show that addition of sodium containing mixtures such as sodium pyruvate, and sodium butyrate improve hemodynamic stability and organ functions in burn patients [24] [25]. Therefore, it would be important to see if these effects would be achieved by modifying the current recommended solutions such that they contain more sodium. In fact, we have previously shown [26] in a retrospective study that when normal saline $(154 \mathrm{mEq} / \mathrm{L})$ was used together with proteins (colloids) as a resuscitative fluid, patients were more likely to have normal sodium blood levels. Cohort in that analysis included 76 patients who received normal saline during the 1 st 12 hours of the shock period followed by $5 \%$ purified plasma 
protein fraction for the rest of the shock period. Another group of 64 patients received 5\% purified plasma protein fraction all through the shock period.

The original Parkland formula as was introduced by Baxter in 1974 recommended the use of colloids in the second 24 hours post burn [3] [27]. On his review paper of different formulas, Greenhalgh mentioned that this recommendation is not usually followed [28]. Those who did not administer colloids in the second 24 hours found that their patients required more resuscitation fluid than predicted by Parkland Formula-a phenomenon termed "fluid creep" [29] [30] [31]. Patients who required more fluids returned to the predicted fluid rates and stayed at lower volumes for the remainder of their resuscitation after giving 5\% albumin [32]. Blumetti et al. had sometimes to give colloids during the first 24 hours in difficult resuscitations [33].

Still, the use of colloids (albumin and dextran) during the initial resuscitation period is controversial. In a meta-analysis of 21 eligible trials involving 1385 critically ill patients' colloids did not improve survival over crystalloids and therefore, were not recommended [17]. However, survival in our cohort was $100 \%$ and this may indicate that mortality during the initial period of resuscitation may not be a sensitive outcome for the importance of colloids and specifically, albumin. This comes as a confirmation of our previous findings of $0 \%$ mortality in our previous similar cohorts and further downgrades this outcome as a legitimate marker of the usefulness of colloids [26]. Additionally, from our experience, deaths that may occur at a later stage may be due to complications such as septic shock and hence albumin may need to be reconsidered for these patients in burn shock phase. Moreover, note that those at the highest risk of death with albumin levels of less than $20 \mathrm{~g} / \mathrm{L}$ [20] were $6(7.3 \%)$ and $15(18.3 \%)$ initially and in the post-resuscitation phases, respectively in this study. It follows that a significant number of our patients may have been at risk of passing away even though none actually expired in the burn shock phase. Furthermore, it is clear in our study that the progressive decline in albumin and protein levels was dramatic and occurred in the entire cohort and all other subgroups analyzed. Consequently, we believe that albumin in addition to current recommended crystalloids may be important for these burn patients although this may need to be confirmed in controlled studies.

Our study is stand-alone to the best of our knowledge in this area of practice which gave a close zoom in at the baseline and post-resuscitation levels of electrolytes, albumin and proteins following RL. Our data consist of a cohort admitted at the major burn unit in the Emirate of Abu Dhabi. Unfortunately, we did not have a comparator arm to contrast the levels with patients who receive albumin in the burn shock phase. This is an important limitation in our study which other groups has to overcome by performing controlled investigations. However, if we take our previous study [26] as a historical control, we find that with a relatively small sample of 140 patients (both arms), providing 5\% human albumin (Purified Plasma Protein Fraction) as the only fluid or combined with normal saline significantly maintained albumin and protein levels. For the sake of comparison, contrast our post-resuscitation mean of albumin of $25.3 \pm 6.3 \mathrm{~g} / \mathrm{L}$ in this study with that of only 
$5 \%$ human albumin (mean of $40.3 \mathrm{~g} / \mathrm{L}$ ) or $5 \%$ human albumin plus normal saline (mean of $37.1 \mathrm{~g} / \mathrm{L}$ ). Lack of clarity as to the optimal fluids to use enabled us to have these different cohorts and hence made it possible to demonstrate the great differences in effect they have on post-resuscitation electrolytes and proteins levels. Nevertheless, we suggest that other centers attempt at replicating our findings and possibly include a reference arm.

It is noteworthy, that larger subgroups were more likely to have significant reductions in sodium and protein levels. They were also more likely to show a beneficial effect of RL on normalization of potassium levels. If we remember that sample size was again a factor that ruled albumin out of the acute management of burn patients, it may be prudent that we conduct larger multicenter studies to finally weigh albumin back in the management of burn patients during the burn shock phase in the future.

\section{Conclusion}

Our study is the first, to authors' best knowledge, in the MENA and GCC regions that demonstrate significant gaps in the management of hypoalbuminemia, hypoproteinemia and to a lesser extent electrolyte imbalance in the burn shock phase in burn patients. These patients may be at risk for significant reductions in albumin and protein levels which put them at an increased risk of death. We recommend using the original Parkland Formula and hence to start colloids after the first 12 24 hours period after crystalloid administration. Hyponatremia correction by adding more sodium, possibly using normal saline or sodium supplementation, may be beneficial. Future studies are needed to replicate our findings and to finally come to an end of the old chapter on albumin in burn patients.

\section{Acknowledgements}

The authors thank Dr. Ayesha Al Qasemi, Head of Pharmacy Department, at Zayed Military Hospital for her continuous support of this research project. They all confirm that they have done this piece in their work time and received no funding from any source.

\section{References}

[1] Tricklebank, S. (2009) Modern Trends in Fluid Therapy for Burns. Burns, 35, 757767. https://doi.org/10.1016/j.burns.2008.09.007

[2] Atiyeh, B.S., Gunn, S.W. and Hayek, S.N. (2005) State of the Art in Burn Treatment. World Journal of Surgery, 29, 131-148. https://doi.org/10.1007/s00268-004-1082-2

[3] Alvarado, R., Chung, K.K., Cancio, L.C. and Wolf, S.E. (2009) Burn Resuscitation. Burns, 35, 4-14. https://doi.org/10.1016/j.burns.2008.03.008

[4] Bacomo, F.K. and Chung, K.K. (2011) A Primer on Burn Resuscitation. Journal of Emergencies, Trauma, and Shock, 4, 109-113. https://doi.org/10.4103/0974-2700.76845

[5] Luo, G., Peng, Y., Yuan, Z., et al. (2009) Fluid Resuscitation for Major Burn Patients with the TMMU Protocol. Burns, 35, 1118-1123.

https://doi.org/10.1016/j.burns.2009.02.020 
[6] Al Benna, S. (2011) Fluid Resuscitation Protocols for Burn Patients at Intensive Care Units of the United Kingdom and Ireland. German Medical Science, 9, 1-7. file:///C:/Users/u0306/Documents/Downloads/GMS-09-14.pdf

[7] Mertens, D.M., Jenkins, M.E. and Warden, G.D. (1997) Outpatient Burn Management. Nursing Clinics of North America, 32, 343.

[8] Woodson, L.C., Sherwood, E.R., Aarsland, A., et al. (2007) Anesthesia for Burned Patients. In: Herndon, D.N., Ed., Total Burn Care, 3rd Edition, Saunders Elsevier, Philadelphia, 196.

[9] Lund, C.C. and Browder, N.C. (1944) The Estimation of Areas of Burns. Surgery Gynecology and Obstetrics, 79, 352.

[10] Monafo, W.W. (1996) Initial Management of Burns. The New England Journal of Medicine, 335, 1581-1586. https://doi.org/10.1056/NEJM199611213352108

[11] Wachtel, T.L., Berry, C.C., Wachtel, E.E. and Frank, H.A. (2000) The Inter-Rater Reliability of Estimating the Size of Burns from Various Burn Area Chart Drawings. Burns, 26, 156-170. https://doi.org/10.1016/S0305-4179(99)00047-9

[12] Perry, R.J., Moore, C.A., Morgan, B.D. and Plummer, D.L. (1996) Determining the Approximate Area of a Burn: An Inconsistency Investigated and Re-Evaluated. BMJ, 312, 1338. https://doi.org/10.1136/bmj.312.7042.1338

[13] Sheridan, R.L., Petras, L., Basha, G., Salvo, P., Cifrino, C., Hinson, M., McCabe, M., Fallon, J. and Tompkins, R.G. (1995) Planimetry Study of the Percent of Body Surface Represented by the Hand and Palm: Sizing Irregular Burns Is More Accurately Done with the Palm. Journal of Burn Care \& Rehabilitation, 16, 605. https://doi.org/10.1097/00004630-199511000-00008

[14] Nagel, T.R. and Schunk, J.E. (1997) Using the Hand to Estimate the Surface Area of a Burn in Children. Pediatric Emergency Care, 13, 254. https://doi.org/10.1097/00006565-199708000-00003

[15] Hidvegi, N., Nduka, C., Myers, S. and Dziewulski, P. (2004) Estimation of Breast Burn Size. Plastic and Reconstructive Surgery, 113, 1591. https://doi.org/10.1097/01.PRS.0000117189.75066.97

[16] Fink, M.P. (2008) Ethyl Pyruvate. Current Opinion in Anesthesiology, 21, 160. https://doi.org/10.1097/ACO.0b013e3282f63c2e

[17] Perel, P. and Roberts, I. (2012) Colloids versus Crystalloids for Fluid Resuscitation in Critically Ill Patients. The Cochrane Database of Systematic Reviews, 6, CD000567. https://doi.org/10.1002/14651858.cd000567.pub5

[18] Huang, P.P., Stucky, F.S., Dimick, A.R., Treat, R.C., Bessey, P.Q. and Rue, L.W. (1995) Hypertonic Sodium Resuscitation Is Associated with Renal Failure and Death. Annals of Surgery, 221, 543. https://doi.org/10.1097/00000658-199505000-00012

[19] Bunn, F., Roberts, I., Tasker, R. and Akpa, E. (2004) Hypertonic versus Near Isotonic Crystalloid for Fluid Resuscitation in Critically Ill Patients. The Cochrane Database of Systematic Reviews, No. 3, CD002045. https://doi.org/10.1002/14651858.CD002045.pub2

[20] Aguayo-Becerra, O.A., Torres-Garibay, C., Macías-Amezcua, M.D., Fuentes-Orozco, C., Chávez-Tostado, M.G., Andalón-Dueñas, E., Espinosa, P.A., Alvarez-Villaseñor, A.S., Cortés-Flores, A.O. and González-Ojeda, A. (2013) Serum Albumin Level as a Risk Factor for Mortality in Burn Patients. Clinics, 68, 940-945. https://doi.org/10.6061/clinics/2013(07)09

[21] Cartotto, R. and Callum, J. (2012) A Review of the Use of Human Albumin in Burn Patients. Journal of Burn Care \& Research, 33, 702-717. 
https://doi.org/10.1097/BCR.0b013e31825b1cf6

[22] Wikipedia Page on Lactated Ringers. https://en.wikipedia.org/wiki/Lactated_Ringer\%27s_solution

[23] Wikipedia Page on Hartmann's Solution. https://en.wikipedia.org/wiki/Hartmann\%27s_solution

[24] Meng, X., Li, J., Bai, X., Hu, S. and Sheng, Z. (2014) The Effects of Sodium Pyruvate Ringer Solution on Hemodynamic and Organ Functions during Shock Stage in Dogs with a 50\% Total Body Surface Area Full-Thickness Burn. Chinese Critical Care Medicine, 26, 244-248.

[25] Liang, X., Wang, R.S., Wang, F., Liu, S., Guo, F., Sun, L., Wang, Y.J., Sun, Y.X. and Chen, X.L. (2013) Sodium Butyrate Protects against Severe Burn-Induced Remote Acute Lung Injury in Rats. PLoS ONE, 8, e68786. https://doi.org/10.1371/journal.pone.0068786

[26] Habib, M.E., Al-Busaidi, S., Latif, G.A., Mehdi, A.S. and Thomas, C. (2013) The Combination of Parkland Formula, Using Normal Saline, with Muir \& Barclay Formula for Fluid Resuscitation in the Initial Burn Shock Period. Modern Plastic Surgery, 3, 142-149. https://doi.org/10.4236/mps.2013.34029

[27] Ioannovich, A.D., Parker, L. and Mantas, N. (1989) Parkland Formula as a Guide for Resuscitation. Annals of the $M B C, 2$.

http://www.medbc.com/annals/review/vol_2/num_1/text/vol2n1p29.htm

[28] Greenhalgh, D.G. (2007) Burn Resuscitation. Journal of Burn Care \& Research, 28, 555-565. https://doi.org/10.1097/BCR.0B013E318093DF01

[29] Mitra, B., Fitzgerald, M., Cameron, P. and Cleland, H. (2006) Fluid Resuscitation in Major Burns. ANZ Journal of Surgery, 76, 35-38.

https://doi.org/10.1111/j.1445-2197.2006.03641.x

[30] Saffle, J.R. (2007) The Phenomenon of "Fluid Creep" in Acute Burn Resuscitation. Journal of Burn Care \& Research, 28, 382-395. https://doi.org/10.1097/BCR.0B013E318053D3A1

[31] Cartotto, R.C., Innes, M., Musgrave, M., Gomez, M. and Cooper, A. (2002) How Well Does the Parkland Formula Estimate Actual Fluid Resuscitation Volumes? Journal of Burn Care \& Rehabilitation, 23, 258-265. https://doi.org/10.1097/00004630-200207000-00006

[32] Endorf, F.W. and Dries, D.J. (2011) Burn Resuscitation. Scandinavian Journal of Trauma, Resuscitation and Emergency Medicine, 19, 69.

[33] Blumetti, J., Hunt, J.L., Arnoldo, B.D., Parks, J.K. and Purdue, G.F. (2008) The Parkland Formula under Fire: Is the Criticism Justified? Journal of Burn Care \& Research, 29, 180-186. https://doi.org/10.1097/BCR.0b013e31815f5a62 